SELAHATTIN KARABAY, M.Sc. ${ }^{1}$

E-mail: selahattin_karabay@hotmail.com

ERKAN KÖSE, Ph.D.2

E-mail: erkankose93@gmail.com

MEHMET KABAK, Ph.D. ${ }^{3}$

E-mail:mkabak@gazi.edu.tr

EREN OZCEYLAN, Ph.D. ${ }^{4}$

(Corresponding author)

E-mail: erenozceylan@gmail.com

1 Turkish Military Academy, Defense Sciences Institute 06654, Ankara, Turkey

2 Aksaray University, Industrial Engineering Department 68100, Aksaray, Turkey

${ }^{3}$ Gazi University, Industrial Engineering Department 06570 Ankara, Turkey

${ }^{4}$ Gaziantep University, Industrial Engineering Department 27310, Gaziantep, Turkey
Transport Logistics

Preliminary Communication

Submitted: May 22, 2015

Accepted: Dec. 8, 2015

\title{
MATHEMATICAL MODEL AND STOCHASTIC MULTI-CRITERIA ACCEPTABILITY ANALYSIS FOR FACILITY LOCATION PROBLEM
}

\begin{abstract}
This paper studies a real-life public sector facility location problem. The problem fundamentally originated from the idea of downsizing the number of service centres. However, opening of new facilities is also considered in case the current facilities fail to fulfil general management demands. Two operation research methodologies are used to solve the problem and the obtained results are compared. First, a mathematical programming model is introduced to determine where the new facilities will be located, and which districts get service from which facilities, as if there were currently no existing facilities. Second, the Stochastic Multi-criteria Acceptability Analysis-TRI (SMAA-TRI) method is used to select the best suitable places for service centres among the existing facilities. It is noted that the application of mathematical programming model and SMAA-TRI integration approach on facility location problem is the first study in literature. Compression of outcomes shows that mixed integer linear programming (MILP) model tries to open facilities in districts which are favoured by SMAA-TRI solution.
\end{abstract}

\section{KEY WORDS}

case study; facility location problem; mixed integer linear programming; Stochastic Multi-criteria Acceptability Analysis; public sector;

\section{INTRODUCTION}

Location-allocation problems seek for locating facilities at candidate sites and assign customers to opened facilities. In public location-allocation problems, all public service demand has to be fulfilled with limited funds. The aim should provide public access to these facilities efficiently and effectively. The access can be measured by travel distance or time to reach these facilities.

A real-life public sector facility location problem is considered in this paper. The problem fundamentally originated from the idea of downsizing the number of service centres. However, opening of new facilities is also considered in case the current facilities fail to fulfil general management demands. The problem analysed in the study takes place in the public sector. The study also sought to find the number of facilities to be located and the facilities that have service capacities. It is a static, single-stage, and a single-product problem that has deterministic input parameters. Given the information, the problem overlaps with the Capacitated Facility Location Problem (CFLP) in literature [15]. The CFLP consists of deciding which facilities to open from a given set of potential facility locations and how to allocate customers to those facilities [16]. If an arbitrary number of customers can be connected to a facility, the problem is called uncapacitated facility location problem (UFLP). If each facility has a limit on the number of customers it can serve, it becomes a capacitated facility location problem [17]. The significance of this work is the utilization of two operation research methodologies to solve a real-life problem. The study can be separated in two parts. In the first part a mathematical programming model is introduced to determine where the new facilities will be located, and which districts get service from which facilities as if there were currently no existing facilities. In the 
second part, the Stochastic Multi-criteria Acceptability Analysis-TRI (SMAA-TRI) is used to decide which facilities should stay open and which facilities should be closed. The compression of outcomes shows that MILP model tries to open the facilities in districts which are favoured by SMAA-TRI solution.

The rest of the paper is organized as follows. In the next section, an overview and a summary of the existing literature of facility location problem and solution approaches is provided. The third section presents the description of the two aforementioned operation research methodologies; Section 4 presents their applications and analyses of the results, and the last section comprises the conclusions about the study.

\section{LITERATURE REVIEW}

This section first presents a brief review on the most relevant and recent literature on facility location problems; followed by the same for SMAA-TRI method and integrated approaches.

\subsection{Literature on Facility Location Problems}

There has been an increasing number of studies about the facility location problems since the $17^{\text {th }}$ century. But, it was Weber [1] who identified the first facility location problem. In this problem, he located a single facility to serve a finite set of demand points with the objective of minimizing the sum of the weighted distances from facility to demand points. Four

Table 1 - Categorization of facility location problems

\begin{tabular}{|c|c|c|}
\hline $\begin{array}{l}\text { Categorization } \\
\text { Subject }\end{array}$ & $\begin{array}{l}\text { Categorization } \\
\text { Types }\end{array}$ & Explanation \\
\hline \multirow{3}{*}{ Topology } & Continuous & $\begin{array}{l}\text { In continuous models, demands are distributed continuously across a service } \\
\text { region and facilities can be located anywhere in that region. }\end{array}$ \\
\hline & Network & $\begin{array}{l}\text { In network models, there is a network composed of links and nodes. De- } \\
\text { mands on nodes and facilities can be located on nodes or links. }\end{array}$ \\
\hline & Discrete & $\begin{array}{l}\text { In discrete location models, there are demands arising on nodes and facili- } \\
\text { ties can be located only on a set of candidate nodes. }\end{array}$ \\
\hline \multirow{2}{*}{ Objective function } & Minsum & Minsum models have the aim to minimize average/total distances. \\
\hline & Minmax & Minmax models have the aim to minimize the maximum distances. \\
\hline \multirow{2}{*}{ Solution method } & Exact algorithms & Algorithms that try to find the optimal solution. \\
\hline & Heuristics & Algorithms that search for an approximate solution. \\
\hline \multirow{2}{*}{ Demand type } & Single-product & The problem includes only one type of product. \\
\hline & Multiple-product & There can be different product types. \\
\hline \multirow{2}{*}{ Supply chain type } & Single-stage & $\begin{array}{l}\text { Single-stage models focus on service distribution systems with only one } \\
\text { stage. }\end{array}$ \\
\hline & Multi-stage & $\begin{array}{l}\text { Multi-stage models consider the flow of service through several hierarchical } \\
\text { levels. }\end{array}$ \\
\hline \multirow[b]{2}{*}{ Time horizon } & Static & Static models optimize the problem deciding all variables simultaneously. \\
\hline & Dynamic & $\begin{array}{l}\text { Dynamic models consider different time periods with data variation across } \\
\text { these periods, and give solutions for each time period adapting to the differ- } \\
\text { ent conditions. }\end{array}$ \\
\hline \multirow[b]{2}{*}{ Input parameters } & Deterministic & $\begin{array}{l}\text { In deterministic models, the parameters are forecast with specific values and } \\
\text { thus the problems are simplified for easy and quick solutions. }\end{array}$ \\
\hline & Stochastic & $\begin{array}{l}\text { Stochastic/probabilistic location models capture the complexity inherent in } \\
\text { real-world problems through probability distributions of random variables or } \\
\text { considering a set of possible future scenarios for the uncertain parameters. }\end{array}$ \\
\hline \multirow{3}{*}{ Number of facilities } & One & The purpose of the problem is locating only one facility. \\
\hline & Certain & Number of facilities to be located is a certain number. \\
\hline & Uncertain & $\begin{array}{l}\text { Number of facilities to be located is uncertain. Problem also searches for the } \\
\text { number of facilities. }\end{array}$ \\
\hline \multirow[b]{2}{*}{ Facility type } & Desirable & Closeness of facility (such as hospital) to demand center is better. \\
\hline & Undesirable & $\begin{array}{l}\text { People want these facilities (such as nuclear reactor) far from demand cen- } \\
\text { ters. }\end{array}$ \\
\hline \multirow{2}{*}{ Sector type } & Private & It seeks for maximizing profit while locating facilities. \\
\hline & Public & Optimization of the population's access is the priority. \\
\hline
\end{tabular}


components play the role of characterizing the location problems. They are customers with demands, facilities to be located, a space in which customers and facilities are located, and finally metric that indicates distances or times between customers and facilities [2]. Common types of location problems in literature are median, covering, centre, and hub-location problems. The $p$-median problem was first introduced by Hakimi [3]. His goal was to find the minimum weighed distance location of $p$ facilities on a demand of $n$ nodes. He also proved that in a network at least one node is optimal to locate a facility. He called the property "node optimality'. By the help of property, search for the optimal solution set is highly reduced. It is proven by Kariv and Hakimi [4] that the general p-median problem is NP-Hard. There were several solution approaches in literature. Some of these solution approaches were introduced in a solution survey for p-median problems [5]. Lim et al. [6] introduced some improvements for these solution approaches. Starting from interchange algorithm by Teitz and Bart [7], in a recent paper, the solution methods were mentioned and a new one was introduced [8]. Hakimi [9] again introduced the covering problem to allocate police stations to the nodes. In covering the problem each customer can be served by each facility in the coverage distance or time. The first MILP model in covering problems was developed by Toregas et al. [10]. Later, Church and ReVelle [11] formulated the maximum covering problem. Several types of covering problems take place in literature (set covering, partial covering, etc.). The p-centre problem consists of locating $\mathrm{p}$ facilities and assigning clients to them in order to minimize the maximum distance between a client and the facility to which they are allocated [12]. Hub location problems aim to locate hubs between arriving and departure points of people, service, information, etc. These hubs are applied to decrease the number of transportation links between origin and destination nodes [13]. Facility location models can be categorized broadly by their topography, objectives, demand allocation types, number of product types, solution methods, features of facilities, supply chain type, time horizon, and input parameters [14]. Table 1 shows categorization of facility location problems based on different aspects.

\subsection{Literature on SMAA-TRI Method}

After the introduction of SMAA by Lahdelma et al. [47], some extensions of SMAA are developed. SMAA3 was introduced and an application was demonstrated by Hokkanen et al. [48]. Instead of choosing the best alternative, a ranking method was introduced with SMAA-2 by Lahdelma and Salminen [49]. Several applications of facility location handled with the method. SMAA-O extends SMAA- 2 to consider ordinal criteria measurements [50]. Ref-SMAA or SMAA-A generates random reference points from the reference point space and evaluates the decision alternatives based on an achievement function [51]. SMAA-TRI was developed for the parameter stability analysis of ELECTRE TRI and extends ELECTRE TRI to allow ignorance on the parameter values [52]. SMAA-D applies efficiency measures of data envelopment analysis, instead of the utility function [53]. One can find some SMAA methods used in location problems. In their paper Hokkanen et al. [54] used SMAA method to choose a location for Helsinki cargo harbour. They had 11 criteria for the problem and most of them were related to nature protection. Lahdelma et al. [55] considered to locate a waste treatment facility by using SMAA-O method. Seventeen criteria with ordinal measurement values took place in their study. Menou et al. [56] used SMAA-O method for centralizing cargo at a Moroccan airport hub with six criteria.

\subsection{Literature on solution approaches for CFLP}

Most research on the CFLP has focused on the development of efficient solution algorithms [18]. Kuehn and Hamburger [19] present one of the earliest models and a heuristic procedure for the CFLP. Davis and Ray [20] used Benders' decomposition to solve CFLP. Akinc and Khumawala [21] developed a branch and bound algorithm by using linear programming relaxation. Jacobsen [22] introduced a variant of CFLP and some heuristics for the problem. The cross-decomposition algorithm of Van Roy [23] and the Lagrangean-based approach of Beasley [24] are among the most effective techniques that were subsequently devised for solving the CFLP. Magnanti and Wong [25] provide an overview of solution methods for CFLP. Delmaire et al. [26] deal with the capacitated single-source plant location problem and describe four heuristic algorithms including GRASP and a taboo search for the problem. Agar and Salhi [27] represented performance of Lagrangean heuristics applied to a variety of CFLPs. Hindi and Pienkosz [28] discuss a large-scale and a single-source CFLP in their paper. Hinojosa et al. [29] consider a two-echelon problem in which plants, warehouses, and customers form a system. To minimize the inventory holding and production set-up costs, Alfieri et al. [30] investigated the capacitated lot-sizing problem. Baldacci et al. [31] formulated the capacitated p-median problem as a set-partitioning problem. Diaz and Fernandez [32] consider a version of CFLP, in which the objective function is to minimize construction and transportation costs. In a study, Ghiani et al. [33] consider a CFLP where they can locate multiple facilities at the same site. Recently a taboo search [34], a multi-exchange heuristic [35], a scatter search algorithm [36], and a hybrid algorithm combining Lagrangean heuristic and ant colony 
system [37] were proposed to solve the single-source CFLP.

One can find a hybrid algorithm to solve CFLP and a comparison with Benders' decomposition algorithm in Lai et al. [38]. Multi-criteria decision analysis (MCDA) methods have also been used to solve location problems. These problems deal with the selection of candidate sites for locating certain facilities so that they optimally fulfil the needs of the users, taking into account some criteria. There are several applications of the MCDA for facility location problems in literature [39, 40, 41, 42]. A comparison of MCDA methodologies for a location problem takes place in a study [43]. One can see / observe several applications that use a single MILP model or an MCDA method in literature but it is the first time SMAA and CFLP are used together in the same facility location problem.

\section{METHODOLOGIES}

Two operation research methodologies are used to solve a real life facility location problem in this study. These methods are briefly mentioned in the following sub-sections.

\subsection{Capacitated Facility Location Problem}

CFLP can be illustrated starting from $p$-median problem. P-median problem is concerned with allocation of $p$ facilities to candidate sites. The objective is the minimization of the average travel distance of customers. For this purpose, we can introduce the following variables and parameters:

I -set of nodes;

$J$-set of candidate sites to locate facilities;

$w_{i}$-demand of node $i$

$d_{i j}$-distance from node $i$ to candidate site $j$;

$x_{j}$-if a facility is located at candidate site $j$, it is 1 and otherwise 0 ;

$y_{i j}$-if demand node $i$ gets service from facility located at $j$, it is 1 and otherwise 0 .

With the notation above the $p$-median problem which is an MILP model is formulated as follows [44]:

$$
\begin{aligned}
& \min \sum_{j \in J} \sum_{j \in J} w_{i} d_{i j} y_{i j} \\
& \text { s.t. } \sum_{j \in J} Y_{i j}=1 \quad \forall i \in I \\
& y_{i j}-x_{j} \leq 0 \quad \forall i \in I, \forall j \in J \\
& \sum_{j \in J} x_{j}=p \\
& x_{j} \in\{0,1\} \quad \forall j \in J \\
& y_{i j} \in\{0,1\} \quad \forall i \in I, \forall j \in J
\end{aligned}
$$

Objective Function 1 minimizes the demand-weighed total distance. Constraint 2 ensures that each demand is assigned to a facility. Constraint 3 demand node is assigned to an open facility. Constraint 4 allows $p$ facilities to be opened. Constraints 5 and 6 are integrity constraints on variables. The proposed model assumes that the costs of all the facility locations at each candidate site are the same. Also the number of facilities is constant. Accordingly, UFLP emerged to overcome the mentioned assumption and make it a more realistic problem. Erlenkotter [45] presents the following formulation of UFLP:

$\min \sum_{j \in J} f_{j} x_{j}+\alpha \sum_{j \in J} w_{i} d_{i j} y_{i j}$

s.t.: Constraints 2, 3, 5, 6.

In the formulation, $f_{i}$ stands for the fixed costs of opening facilities. Objective Function 7 minimizes the total fixed and variable costs. Again, Constraint 2 ensures that all the demand is assigned, whereas they are assigned to opened facilities as required by Constraint 3 . UFLP assumes that the facilities have limitless service capacity unlike real world situations. With a capacity constraint the problem seems to be more realistic. This type of UFLP is called the CFLP. Let $a_{i}, i \in I$, be the customer's demands and $b_{j}$ the facility's capacity. Then the CFLP is formulated as:

$$
\begin{array}{r}
\min \sum_{j \in J} f_{j} x_{j}+\sum_{j \in J} \sum_{i \in l} C_{i j} Y_{i j} \\
\text { s.t.: 2, 5, } 6 \text { and Constraint } 9 .
\end{array}
$$

$$
\sum_{i \in l} a_{i} y_{i j}-b_{j} x_{j} \leq 0 \quad \forall i \in I, \forall j \in J
$$

Constraint 9 provides the opened facilities service at most their capacity. It is noted that the models expressed from 1 to 9 refer to MILP, since two kinds of variables are involved, integer based, and real number based (costs, distances).

\subsection{Stochastic Multi-criteria Acceptability Analysis (SMAA)}

A variety of MCDA methods need criterion measurements from decision-makers. It is not always possible to get all these information, especially in public political problems. Besides, they require preference information for describing the relative importance of different criteria. One of the advantages of SMAA over most other MCDA methods is that it can be used without any preference information [46]. SMAA has been proposed for problems which criteria values and weights are not correctly known. Stochastic variables $\xi_{i j}$ with accepted or estimated joint probability distribution and density function $f(\xi)$ in space $X$ show uncertain or guessed criteria values. In addition, decision-makers' unknown or partly known preferences are symbolized by a weight distribution with density function $f(w)$ in the set of feasible weights $W$ defined as 
$W=\left\{w \in R^{n}: w \geq 0\right.$ and $\left.\sum_{j} w_{j}=1\right\}$

The utility function is then used to map stochastic criteria and weight distributions into utility distributions $\left(u\left(\xi_{i}\right), w\right)$. The SMAA method concludes for each alternative the set of favourable weights $W_{i}(\xi)$ described as

$W_{i}(\xi)=\left\{w \in W: u\left(\xi_{i, w}\right) \geq u\left(\xi_{k, w}\right), \forall_{k}\right\}$

The properties of these sets direct all additional analyses. SMAA uses three main measurements [49]:

- The first measure is the acceptability index $a_{i}$ which is described as the expected ( $n-1)$ dimensional volume of the approvable weights. It is figured out as a multidimensional integral over the criteria distributions $\xi$ and approvable weight space as

$a_{i}=\int_{X} f(\xi) \int_{W_{i}(\xi)} f(w) d w d \xi$

The acceptability index can be used for labelling the alternatives into more or less acceptable ones $(a>0)$, and those which are not acceptable $\left(a_{i}\right.$ zero or near zero). For the case with two criteria, deterministic values and a linear utility function, the approvable weights and acceptability indices can be clarified graphically as in Figure 1.

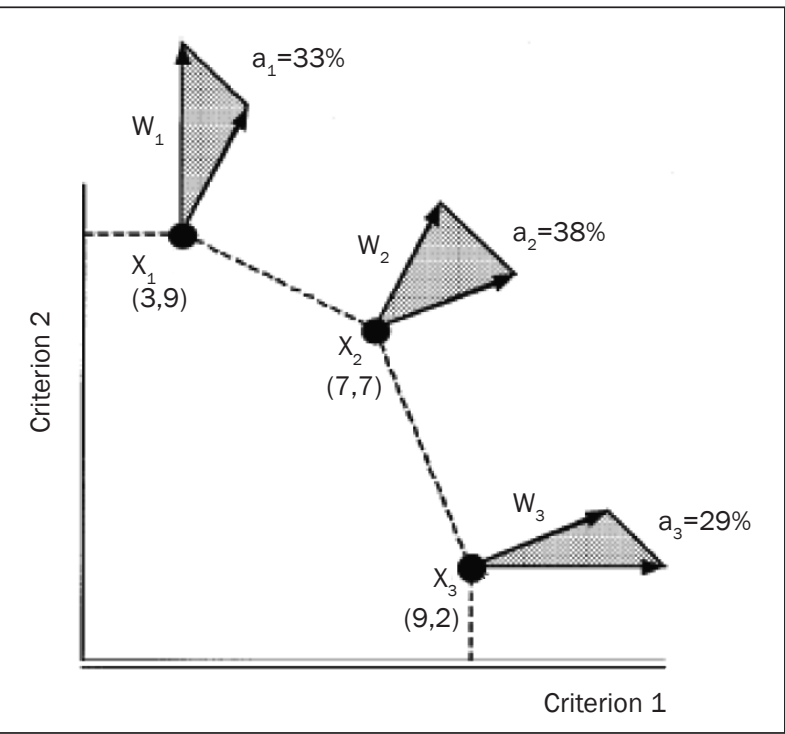

Figure 1 - Approvable weights and acceptability indices

- The central weight vector $w_{i}^{c}$ is described as the expected centre of gravity of the approvable weight space. The central weight vector is figured out as an integral of the weight vector over the criteria and weight distributions by

$w_{i}^{C}=\int_{x} f(\xi) \int_{W_{i}(\xi)} f(w) w d w d \xi / a_{i}$

DMs can find out how different weights correspond to different choices by using the central weights.

- The confidence factor $P_{i}^{c}$ is described as the probability for the alternative to be the picked one if the central weight vector is elected. The confidence factor is figured out as an integral over the criteria distributions $\xi$ by

$p_{i}^{c}=\int \xi: u\left(\xi i, w_{i}^{c}\right) \geq u\left(\xi_{k, w_{i}^{c}} f(\xi) d \xi\right.$

The confidence factor measures whether the criteria data are correct enough to determine the alternatives when the central weight vector is used. More detailed information about the SMAA can be easily obtained from the papers [47, 49]. The decision makers in public political decision situation prefer methods that do not require them to express their preferences explicitly, but rather describe their consequences in an appropriate form, in order to allow the final decision to be made by themselves and SMAA has been developed to support decision makers in public environmental multicriteria decision-making [47]. There are three main MCDA problem statements: choosing, ranking and sorting [57]. Table 2 shows the decision tree to choose the SMAA method for a specific probIem. SMAA-TRI is the first SMAA method for the sorting problem statement. Dividing alternatives into groups are among favourite research fields in various disciplines. The SMAA-TRI is one of the useful methods for sorting, because it does not need weight elicitation [58]. The method is an improved form of ELECTRE-TRI to use stochastic values.

\section{APPLICATIONS}

The topic of the study is a real life facility location problem in public sector institution. Because of the restriction of the institution, city and region names are not mentioned, instead they are coded by $D_{1}, \ldots$ $D_{55}$. The institution currently has 24 service facilities in a region. That region has 55 districts $\left(D_{1}-D_{55}\right)$ and 6 of them are central districts $\left(D_{1}, D_{12}, D_{22}, D_{32}, D_{42}\right.$, and $\left.D_{55}\right)$. The cities which are coded by " $D_{1}, D_{12}, D_{22}$, $D_{32}, D_{42}, D_{52}$ " are central districts as mentioned in the study.

A district which has not got a facility gets service from another facility in that region. General management desires to reduce the number of facilities. If necessary, additional facilities can be opened but the first aim is to close some facilities. Also, after the new system is established, they want to make the new allocations of districts to the facilities. The facilities in the system are of five different types with different capacities. The management demands a new system, because the existing system no longer provides an adequate and cost-effective service. The reasons for this change can be listed as follows:

- Change of population within the districts due to migration. Some facilities have enormous work to do, while others have residual capacities.

- Change in the transportation technology and transportation ways. 
Table 2 - Decision-tree to choose the SMAA variant [46]

\begin{tabular}{||l|l|l|l|l||}
\hline Problem Statement? & Ranking & & & Sorting \\
\hline \hline Reference model? & Weight of scaling factor & & Reference points & \\
\hline $\begin{array}{l}\text { Aggregating } \\
\text { procedure? }\end{array}$ & Utility or value function & Outranking procedure & Achievement function & \\
\hline Method & SMAA-2 & SMAA-3 & Ref SMAA & SMAA TRI \\
\hline Descriptive measures & $\begin{array}{l}\text { - Cross confidence } \\
\text { factors } \\
\text { - Rank acceptability } \\
\text { indices } \\
\text { - Acceptability indices } \\
\text { - Central weight vectors }\end{array}$ & $\begin{array}{l}\text { - Acceptability indices } \\
\text { - Central weight } \\
\text { vectors }\end{array}$ & $\begin{array}{l}\text { - Central reference } \\
\text { points } \\
\text { - Reference accept- } \\
\text { ability indices }\end{array}$ & indices \\
\hline Aggregate measures & $\begin{array}{l}\text { - Holistic acceptability } \\
\text { indices } \\
\text { - kbr acceptability } \\
\text { indices }\end{array}$ & & \\
\hline
\end{tabular}

- Downsizing lets the management use the remaining workers in other works.

- Closed facility buildings will be used by other public institutions.

- Savings from the reduced facility expenditures and worker fees.

Two operation research methodologies are used to solve the problem. First, a mathematical programming model is introduced to determine where the new facilities will be located, and which districts get service from which facilities as if there are currently no existing facilities. Second, the SMAA-TRI method is used to determine which facilities should stay open and which facilities should be closed.

\subsection{MILP model application}

The work uses the CFLP model in literature with some problem-specific constraints. General management has some demands for establishing the new system. These demands can be listed as follows:

- There must be facilities in central districts.

- The location of the facility should have enough security and development level.

- For the service policy, citizens should not travel more than $90 \mathrm{~km}$ to reach a facility.

To solve the location-allocation problem proposed integer-programming model is illustrated below.

Sets:

$\mathrm{N}$ - set of districts to get service and set of sites to locate facilities;

$\mathrm{N}_{1}$ - set of districts that has facility;

$\mathrm{N}_{2}$ - set of districts that does not have facility;

$\mathrm{N}_{c}$ - set of central districts $\left(\mathrm{D}_{1}, \mathrm{D}_{12}, \mathrm{D}_{22}, \mathrm{D}_{32}, \mathrm{D}_{42}, \mathrm{D}_{52}\right)$;

$\mathrm{N}_{\mathrm{S}}$ - set of districts which has required security level (the districts other than “D3, D6, D25, D44”);
$\mathrm{N}_{d}$ - set of districts which has required development level (the districts other than " $D_{2}, D_{7}, D_{31}, D_{41}$, $\mathrm{D}_{54}$ ");

$\mathrm{T}$ - set of facility types (facilities are grouped into different classes based on the number of workers. While there are 25-35 workers in a type A facility, 3-5 workers serve in a type E facility. The other numbers for each type of facility are: $\mathrm{B}=18 ; \mathrm{C}=10-12 ; \mathrm{D}=5-8$ )

Input parameters:

$W_{i}$ - population of district $i$

$C_{k}$ - capacity of $k$ type facility;

$M_{k^{-}}$annual operating cost of $k$ type facility;

$F_{k}$ - fixed cost of opening $k$ type facility;

$d_{i j}$ - distance from district $i$ to site $j$ in $\mathrm{km}$.

Constants:

C - travel cost per km;

$\delta$ - specific distance in accordance with the request.

Decision variables:

$x_{i j}=\left\{\begin{array}{c}1 \text { if district } i \text { gets service from facility } j, \\ 0 \text { otherwise }\end{array}\right.$

$y_{i j}=\left\{\begin{array}{c}1 \text { if } k \text { type of facility opened at node } j, \\ 0 \text { otherwise }\end{array}\right.$

Objective function:

$$
\begin{aligned}
\min = & \sum_{i \in N} \sum_{j \in N} W_{i} d_{i j} x_{i j} c+ \\
& +\sum_{j \in N_{2}} \sum_{k \in T} F_{k} y_{j k}+\sum_{j \in N} \sum_{k \in T} M_{k} y_{j k}
\end{aligned}
$$

Objective function minimizes the weighted travel distance of customers to facilities, fixed facility opening costs, and operating costs of facilities for a certain period. Fixed facility opening costs for currently existing facilities are taken as zero in calculation.

Constraints:

s.t. 


$$
\begin{array}{ll}
\sum_{j \in N} x_{i j}=1 & \forall i \\
\sum_{k \in T} y_{i k} \leq 1 & \forall j \\
\sum_{i \in N} x_{i j} \leq n \sum_{k \in T} y_{j k} & \forall j \\
\sum_{k \in T} y_{j k} c_{k} \geq \sum_{i \in N} x_{i j} W_{i} & \forall j \\
x_{i j} d_{i j} \leq \delta & \forall i, j \\
\sum_{j \in N_{c}} \sum_{k \in T} Y_{j k} \geq n & \forall j \notin N \text { s } \\
\sum_{k \in T} y_{j k}=0 & \forall j \in N_{d} \\
\sum_{k \in T} y_{j k}=0 & \forall i \in N, \forall j \in N \\
x_{i j} \in\{0,1\} & \forall j \in N, \forall k \in T \\
y_{j k} \in\{0,1\} &
\end{array}
$$

We guarantee all districts to be assigned a facility with Constraint 16, and there will be only one kind of facility, if opened in the candidate site by Constraint 17. To be in accordance with first request, Constraint 21 is added to the model. This constraint ensures the locating at least one kind of facility in those central districts. General management divided districts into 5 security level based on management's subjective assessment. There is no desire to locate a facility in a district which is in the lowest security level. Constraint 22 is added to the model in order to avoid opening facilities at districts which has not enough security level. General management's requests about district development level are reflected to the model with the data provided by Ministry of Development [60]. Ministry of Development calculated all the districts' development indexes and put them into 6 development group. A part of the work is shown in Table 3. As it can be seen from the Table 3, D1 is more developed district than D2 with the smaller development order and higher development index. Under development boundaries are represented by the minus numbers in Table 3.

Constraint 23 provides opening facilities at districts which have sufficient development level. Constraint 20 ensures the third demand of general management. A sample of distance matrix which shows distance between districts is shown in Table 4.

Constraint 18 links $x_{i j}$ and $y_{i j}$ variables. They state that if there is an open facility it can serve districts; otherwise, no districts can be assigned to it. The capacity Constraint 19 prevents facilities from serving population more than they can. The capacities are found by calculating a worker's daily capacity of service and former experiences. Finally, Constraints 24 and 25 are integrity constraints on variables. The proposed model with 55-node locations has 3,300 discrete variables and 3,190 constraints. GAMS IDE 2.0.34.19 program is used to solve the problem and find an exact solution. The comparison of CFLP solution and the existing facility settlement is shown in Table 5. The CFLP solution indicates that 11 currently existing facilities should be closed $\left(D_{2}, D_{7}, D_{8}, D_{10}, D_{11}, D_{24}, D_{38}, D_{41}, D_{49}, D_{50}\right.$, $\left.D_{51}\right)$ and 3 new facilities should be opened $\left(D_{14}, D_{18}\right.$, $D_{55}$ ). According to the results, the management can reduce the number of facilities by 8 .

Table 3 - District development matrix

\begin{tabular}{||c|c|c|c||}
\hline \hline District & $\begin{array}{c}\text { Development } \\
\text { order }\end{array}$ & $\begin{array}{c}\text { Development } \\
\text { group }\end{array}$ & $\begin{array}{c}\text { Development } \\
\text { index }\end{array}$ \\
\hline \hline$D_{1}$ & 145 & 2 & 0.75922 \\
\hline$D_{2}$ & 827 & 6 & -1.17754 \\
\hline$\ldots$ & $\ldots$ & $\ldots$ & $\ldots$ \\
\hline$D_{54}$ & 821 & 6 & -1.15538 \\
\hline$D_{55}$ & 763 & 6 & -0.83619 \\
\hline
\end{tabular}

Table 4 - Distance matrix between districts

\begin{tabular}{|c|c|c|c|c|c|c|c||}
\hline \hline District & $\mathrm{D}_{1}$ & $\mathrm{D}_{2}$ & $\mathrm{D}_{3}$ & $\ldots$ & $\mathrm{D}_{53}$ & $\mathrm{D}_{54}$ & $\mathrm{D}_{55}$ \\
\hline \hline $\mathrm{D}_{1}$ & - & 61 & 36 & $\ldots$ & 201 & 241 & 215 \\
\hline $\mathrm{D}_{2}$ & & - & 64 & $\ldots$ & 152 & 189 & 209 \\
\hline $\mathrm{D}_{3}$ & & & - & $\ldots$ & 251 & 240 & 220 \\
\hline$\ldots$ & & & & - & $\ldots$ & $\ldots$ & $\ldots$ \\
\hline $\mathrm{D}_{53}$ & & & & & - & 181 & 61 \\
\hline $\mathrm{D}_{54}$ & & & & & & - & 121 \\
\hline $\mathrm{D}_{55}$ & & & & & & & - \\
\hline
\end{tabular}

\subsection{SMAA-TRI Application}

In this section SMAA-TRI is used to decide which facilities should stay open and which facilities should be closed based on the criteria determined by the general management. The reasons for choosing SMAA-TRI as a solution method are as follows:

- Some criteria measurements are imprecise.

- As it is a public political decision there are several decision-makers. So, it is difficult to get exact preference information from them.

- The weights of criteria are imprecise. Only the hierarchy of criteria importance is provided by decision-makers.

- This is a sorting process of facilities into two groups (stay open or closed).

General management demands that each central district has a facility. Currently, 6 of 24 facilities stand in the central districts $\left(D_{1}, D_{12}, D_{22}, D_{32}, D_{42}\right.$, and $\left.D_{52}\right)$. So, the selection problem can be reduced to decide which of the 18 non-central facilities should stay open. The following criteria are specified by the general management (Table 6).

General management provides the order of importance of these criteria, but not preference informa- 
Table 5 - Comparison of CFLP solution and existing facility settlement

\begin{tabular}{|c|c|c|c|c|c|c|c|c|c|c|c|}
\hline \multirow{2}{*}{ Existing facilities } & \multicolumn{5}{|c|}{ Facility Types } & \multirow{2}{*}{ Model proposal } & \multicolumn{5}{|c|}{ Facility Types } \\
\hline & $\bar{A}$ & $\mathrm{~B}$ & C & $\mathrm{D}$ & $\bar{E}$ & & $\bar{A}$ & $\bar{B}$ & C & $\bar{D}$ & $\bar{E}$ \\
\hline $\mathrm{D}_{1}$ & $x$ & & & & & $\mathrm{D}_{1}$ & & & $x$ & & \\
\hline $\mathrm{D}_{2}$ & & & & $x$ & & $\mathrm{D}_{9}$ & & & & & $x$ \\
\hline $\mathrm{D}_{7}$ & & & $x$ & & & $D_{12}$ & & $x$ & & & \\
\hline $\mathrm{D}_{8}$ & & & & $x$ & & $D_{14}$ & & & & & $x$ \\
\hline $\mathrm{D}_{9}$ & & $\mathrm{x}$ & & & & $D_{18}$ & & & & & $x$ \\
\hline$D_{10}$ & & & & $x$ & & $\mathrm{D}_{21}$ & & & & $x$ & \\
\hline$D_{11}$ & & & $x$ & & & $\mathrm{D}_{22}$ & & & & $x$ & \\
\hline$D_{12}$ & $x$ & & & & & $\mathrm{D}_{23}$ & & & & & $x$ \\
\hline$D_{21}$ & & $\mathrm{x}$ & & & & $D_{31}$ & & & & & $x$ \\
\hline $\mathrm{D}_{22}$ & & $x$ & & & & $D_{32}$ & & & & $x$ & \\
\hline$D_{23}$ & & & $\mathrm{x}$ & & & $D_{39}$ & & & & & $x$ \\
\hline$D_{24}$ & & & $x$ & & & $\mathrm{D}_{40}$ & & & & $x$ & \\
\hline$D_{31}$ & & 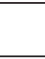 & & $x$ & & $\mathrm{D}_{42}$ & & $x$ & & & \\
\hline$D_{32}$ & & $x$ & & & & $\mathrm{D}_{43}$ & & & & $x$ & \\
\hline$D_{38}$ & & & $x$ & & & $D_{52}$ & & & & $x$ & \\
\hline$D_{39}$ & & & $x$ & & & $D_{55}$ & & & & & $x$ \\
\hline $\mathrm{D}_{40}$ & & $x$ & & & & Total & 0 & 2 & 1 & 6 & 7 \\
\hline $\mathrm{D}_{41}$ & & & $x$ & & & & & & & & \\
\hline $\mathrm{D}_{42}$ & $x$ & & & & & & & & & & \\
\hline $\mathrm{D}_{43}$ & & $\mathrm{x}$ & & & & & & & & & \\
\hline $\mathrm{D}_{49}$ & & & $x$ & & & & & & & & \\
\hline$D_{50}$ & & & & $x$ & & & & & & & \\
\hline$D_{51}$ & & & $x$ & & & & & & & & \\
\hline$D_{52}$ & & & $x$ & & & & & & & & \\
\hline Total & 3 & 6 & 10 & 5 & 0 & & & & & & \\
\hline
\end{tabular}

Table 6 - Criteria for SMAA-TRI

\begin{tabular}{||l|l||}
\hline \multicolumn{1}{|c|}{ Criteria } & \multicolumn{1}{|c||}{ Explanation } \\
\hline \hline C1-Population of district (Number) & $\begin{array}{l}\text { The criterion shows us the number of people getting service from that facility. } \\
\text { Of course, districts, which have dense population, have more chance to stay } \\
\text { open. }\end{array}$ \\
\hline $\begin{array}{l}\text { C2-Distance to central district (Dis- } \\
\text { tance) }\end{array}$ & $\begin{array}{l}\text { Town centers are sure to be opened. So the criterion reflects the distance } \\
\text { between facility location and central district. The desire of general manage- } \\
\text { ment is to close facilities which are near to the central districts. }\end{array}$ \\
\hline C3-Operating cost (Cost) & The criterion shows the annual operating cost of the facility. \\
\hline C4-Development level (Development) & $\begin{array}{l}\text { The criterion shows the development level of districts. For general manage- } \\
\text { ment, the development level of facilities which will remain open needs to be } \\
\text { sufficiently higher. }\end{array}$ \\
\hline C5-Security level (Security) & $\begin{array}{l}\text { The security levels of all districts in the region are evaluated by the general } \\
\text { management according to their experiences. General management desires } \\
\text { that the facilities which will remain open should be secure enough. }\end{array}$ \\
\hline C6-Building condition (Building) & The criterion shows the condition of buildings. \\
\hline
\end{tabular}


tion. Without the precise weight information of criteria ordinal hierarchy for them is provided by the general management. The order of criteria is shown as follows: $\mathrm{C}_{1} \geq \mathrm{C}_{2} \geq \mathrm{C}_{6} \geq \mathrm{C}_{5} \geq \mathrm{C}_{4} \geq \mathrm{C}_{3}$. With these criteria the facilities are categorized into two groups. The first group shows the facilities which will remain open, while the second one forms the group of facilities to be closed. Tervonen [59] provided JSMAA program which is an open source implementation in Java for the solution of SMAA-2 and SMAA-TRI problems. In this study, JSMAA program is used for the SMAA-TRI application. In the study, eighteen alternatives, six criteria and two categories are described, respectively. Preferences can be chosen as missing, ordinal or cardinal. "Ordinal" has been chosen and criteria are ranked 1 to 6 by DMs. Measurement values for alternatives could be described as exact, interval, Gaussian, lognormal, logitnormal, beta and discrete. Researchers can find more information for the JSMAA at the website (http:// smaa.fi/jsmaa/). JSMAA is used to group alternative as suitable enough to remain open or not. The output of the program reveals the category acceptability indices of all alternatives. These indices show how much an alternative fits that category. Table 7 shows the category acceptability indices of alternatives. The method proposes to close eight facilities. Those are $D_{2}, D_{7}$, $D_{8}, D_{10}, D_{11}, D_{24}, D_{31}$, and $D_{41}$. According to category acceptability indices in Table $7 ; D_{9}, D_{21}, D_{23}, D_{38}, D_{39}$, $\mathrm{D}_{40}, \mathrm{D}_{43}, \mathrm{D}_{49}, \mathrm{D}_{50}$ and $\mathrm{D}_{51}$ should stay open.

Table 8 - Models comparison
Table 7 - Results of SMAA-TRI

\begin{tabular}{|c|c|c|}
\hline \multirow{2}{*}{} & \multicolumn{2}{|c|}{ Category acceptability indices } \\
\cline { 2 - 3 } & CLOSE & REMAIN OPEN \\
\hline \hline$D_{2}$ & 0.55 & 0.45 \\
\hline$D_{7}$ & 0.98 & 0.02 \\
\hline$D_{8}$ & 0.58 & 0.42 \\
\hline$D_{9}$ & 0 & 1 \\
\hline$D_{10}$ & 0.84 & 0.16 \\
\hline$D_{11}$ & 0.54 & 0.46 \\
\hline$D_{21}$ & 0 & 1 \\
\hline$D_{23}$ & 0.14 & 0.86 \\
\hline$D_{24}$ & 0.54 & 0.46 \\
\hline$D_{31}$ & 0.98 & 0.02 \\
\hline$D_{38}$ & 0 & 1 \\
\hline$D_{39}$ & 0.08 & 0.92 \\
\hline$D_{40}$ & 0 & 1 \\
\hline$D_{41}$ & 0.9 & 0.1 \\
\hline$D_{43}$ & 0 & 1 \\
\hline$D_{49}$ & 0.13 & 0.87 \\
\hline$D_{50}$ & 0.13 & 0.87 \\
\hline$D_{51}$ & 0.03 & 0.97 \\
\hline & & \\
\hline
\end{tabular}

Table 8 illustrates the results of two methodologies. MILP model proposes the closing of eleven existing facilities and opening of three new facilities. SMAA-TRI

\begin{tabular}{|c|c|c|c|c|c|}
\hline \multicolumn{3}{|c|}{ MILP MODEL } & \multicolumn{2}{|c|}{ SMAA-TRI } & \multirow{2}{*}{$\begin{array}{c}\text { BOTH } \\
\text { Both models pro- } \\
\text { pose to close }\end{array}$} \\
\hline $\begin{array}{l}\text { MILP model pro- } \\
\text { poses to open }\end{array}$ & $\begin{array}{l}\text { MILP model pro- } \\
\text { poses to close }\end{array}$ & $\begin{array}{l}\text { MILP model pro- } \\
\text { poses to remain } \\
\text { open }\end{array}$ & $\begin{array}{c}\text { SMAA-TRI } \\
\text { proposes to close }\end{array}$ & $\begin{array}{c}\text { SMAA-TRI } \\
\text { proposes to } \\
\text { remain open }\end{array}$ & \\
\hline$D_{14}$ & $\mathrm{D}_{2}$ & $D_{1}$ & $\mathrm{D}_{2}$ & $D_{1}$ & $\mathrm{D}_{2}$ \\
\hline $\mathrm{D}_{18}$ & $\mathrm{D}_{7}$ & $\mathrm{D}_{9}$ & $\mathrm{D}_{7}$ & $D_{9}$ & $\mathrm{D}_{7}$ \\
\hline \multirow[t]{14}{*}{$D_{55}$} & $\mathrm{D}_{8}$ & $\mathrm{D}_{12}$ & $\mathrm{D}_{8}$ & $D_{12}$ & $\mathrm{D}_{8}$ \\
\hline & $\mathrm{D}_{10}$ & $\mathrm{D}_{21}$ & $D_{10}$ & $D_{21}$ & $D_{10}$ \\
\hline & $D_{11}$ & $\mathrm{D}_{22}$ & $D_{11}$ & $D_{22}$ & $D_{11}$ \\
\hline & $D_{24}$ & $D_{23}$ & $\mathrm{D}_{24}$ & $D_{23}$ & $D_{24}$ \\
\hline & $D_{38}$ & $D_{31}$ & $D_{31}$ & $D_{32}$ & $\mathrm{D}_{41}$ \\
\hline & $\mathrm{D}_{41}$ & $D_{32}$ & $\mathrm{D}_{41}$ & $D_{38}$ & \\
\hline & $\mathrm{D}_{49}$ & $D_{39}$ & & $D_{39}$ & \\
\hline & $D_{50}$ & $\mathrm{D}_{40}$ & & $\mathrm{D}_{40}$ & \\
\hline & $D_{51}$ & $\mathrm{D}_{42}$ & & $\mathrm{D}_{42}$ & \\
\hline & & $\mathrm{D}_{43}$ & & $\mathrm{D}_{43}$ & \\
\hline & & $D_{52}$ & & $D_{49}$ & \\
\hline & & & & $D_{50}$ & \\
\hline & & & & $D_{51}$ & \\
\hline & & & & $D_{52}$ & \\
\hline
\end{tabular}




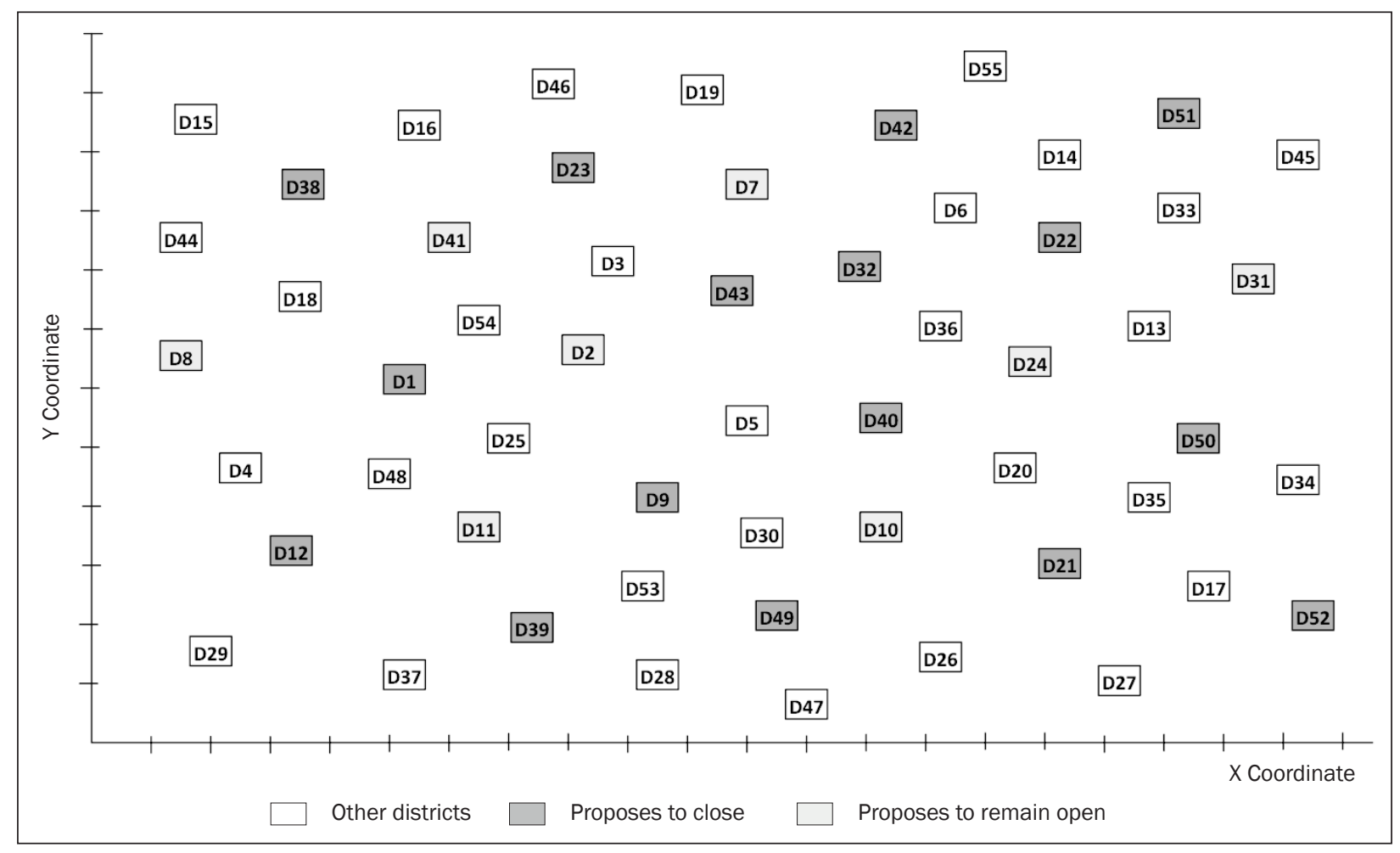

Figure 2 - Results of SMAA-TRI

solution offers to close eight existing facilities. The results of two applications agree on closing seven same facilities. Comparison of outcomes shows that SMAATRI yields very close solution to optima (Figure 2).

In the first part of the application, a mathematical model with 55-node locations has 3,300 discrete variables and 3,190 constraints are built for the problem and GAMS IDE 2.0.34.19 program is used to solve it. The MILP model cannot represent imprecise criteria measurements and weights. So, it is not capable to reflect subjective assessments. In this study SMAA-TRI method is used to overcome the challenge of imprecise evaluation.

The main contribution of this study is proposing two operation research methodologies, namely MILP and SMAA-TRI to eliminate the weaknesses of each other while solving a real life problem. It is considered that in this way more reliable solution alternatives can be proposed to decision makers. SMAA-TRI model which yields very similar results to optima can be easily built by other researchers. In addition, a hybrid MILP-SMAA-TRI model is the first built solving facility location problem.

\section{CONCLUSION}

Facility location is an important problem due to high cost of unfavourable site selection. This problem is especially troublesome in public sector because of political and several other reasons. Including many kinds of uncertainties in the process it is really difficult to make an unfailing decision. In these circumstances, there is always a feeling of some deficiency if the solution is based on a single approach. In order to overcome this, more than one methodology should be used to solve real-life public sector facility location problems.

In this study two eligible approaches have been used to solve a real-life public sector facility location problem. First, a mathematical programming model is introduced to determine where the new facilities will be located, and which districts get service from which facilities as if there are currently no existing facilities. Second, the SMAA-TRI method is used to select the best suitable places for service centres among the existing facilities. Compression of outcomes shows that MILP model tries to open facilities in districts which are favoured by the SMAA-TRI solution. The use of an SMAA-TRI approach allows for the explicit incorporation of uncertainty parameters in the model. An appealing characteristic of the outranking model applied in SMAA-TRI is that it allows the veto effect to be modelled, meaning that a poor performance in one criterion cannot be compensated for by good performance in other criteria.

To the best knowledge of the authors, this paper is the first study which applies mathematical programming model and SMAA-TRI integration on facility location problem. For future studies, (i) application of ELECTRE-TRI method, and (ii) meta-heuristic approaches for MILP model should be suggested. 


\section{ACKNOWLEDGMENT}

The authors express sincere appreciation to the editor and anonymous reviewers for their efforts to improve the quality of this paper. The last author was supported by the BAGEP Award of the Science Academy.

\section{SELAHATTIN KARABAY ${ }^{1}$}

E-posta: selahattin_karabay@hotmail.com Dr. ERKAN KÖSE ${ }^{2}$

E-posta: erkankose93@gmail.com

Doç. Dr. MEHMET KABAK ${ }^{3}$

E-posta: mkabak@gazi.edu.tr

Yrd. Doç. Dr. EREN OZCEYLAN ${ }^{4}$

E-posta: erenozceylan@gmail.com

${ }^{1}$ Kara Harp Okulu, Savunma Bilimleri Enstitüsü 06654, Ankara, Türkiye

${ }^{2}$ Aksaray University, Industrial Engineering Department 68100, Aksaray, Turkey

${ }^{3}$ Gazi Üniversitesi, Endüstri Mühendisliği Bölümü 06570 Ankara, Türkiye

${ }^{4}$ Gaziantep Üniversitesi, Endüstri Mühendisliği Bölümü 27310, Gaziantep, Türkiye

\section{MATEMATIKSEL MODEL VE STOKASTIK ÇOK KRITERLI KABUL EDILEBILIRLIK ANALIZI ILE BIR KAMU KURUMU ICCIN TESIS YERI SEÇIMI}

\section{ÖZET}

Bu çalışmada bir kamu kurumuna ait gerçek bir tesis yeri seçimi problemi ele alınmıștır. illk olarak sistemde il merkezlerindeki tesisler dışında hiç bir tesis yokmuş gibi yeni tesislerin nerelere yerleştirilmesi gerektiği ve hangi ilçelerin hangi tesislerden hizmet alacağı bir matematiksel programlama modeli ile belirlenmeye çalışılmıştır. Daha sonra mevcut tesisler arasında, kamu kurumunun sahip olmasın istediği niteliklerden en fazlasına sahip olanlar Stokastik Çok Kriterli Kabul Edilebilirlik Analizi-TRI (SMAA-TRI) metodu ile tespit edilmiştir. Elde edilen sonuçlar karşılaştırıldığında matematiksel modelin açılmasını önerdiği tesislerin SMAATRI çözümünde de tercih edilen tesisler olduğu görülmüştür.

\section{ANAHTAR KELIMELER}

Vaka Analizi; Tesis Yerleşim Problemi; Karma Tamsayıl Doğrusal Programlama; Stokastik Çok Kriterli Kabul Edilebilirlik Analizi; Kamu Sektörü;

\section{REFERENCES}

[1] Weber A. About the location of industries [in German]. Erster Teil: Reine Theorie des Standortes; 1909.

[2] ReVelle CS, Eiselt HA. Location analysis: A synthesis and survey. Eur J Oper Res. 2005 Aug;165(1):1-19.

[3] Hakimi SL. Optimum locations of switching centres and the absolute centres and medians of a graph. Oper Res. 1964 May;12(3):450-459.

[4] Kariv O, Hakimi SL. An algorithmic approach to network location problems. Part II: The p-median. SIAM J Applied Math. 1979 Dec;37(3):539-560.
[5] Reese J. Solution methods for the p-median problem: an annotated bibliography. Networks. 2006 Aug;48(3):125-142.

[6] Lim GJ, Reese J, Holder A. Fast and robust techniques for the euclidean p-median problem with uniform weights. Comp \& Ind Eng. 2009 Oct;57(3):896-905.

[7] Teitz MB, Bart P. Heuristic methods for estimating the generalized vertex median of a weighted graph. Oper Res. 1968 Oct;16(5):955-961.

[8] Aguado JS, Trandafir PC. Some heuristic methods for solving $\mathrm{p}$-median problems with a coverage constraint. Euro J Oper Res. 2012 July;220(2):320-327.

[9] Hakimi SL. Optimum distribution of switching centres in a communication network and some related graph theoretic problems. Oper Res. 1965 June;13(3): 462-475.

[10] Toregas C, Swain R, ReVelle C, Bergman L. The location of emergency services facilities. Oper Res. 1971 Oct;19(6):1363-1373.

[11] Church R, ReVelle $C$. The maximal covering location problem. Papers Reg Sci Assoc. 1974 Dec;32(1): 101-118.

[12] Daskin MS. Network and discrete location: Models, algorithms, and applications. New York, NY: Wiley; 1995.

[13] Alumur S, Kara BY. Network hub location problems: The state of the art. Euro J Oper Res. 2008 Oct;190(1): 1-21.

[14] Klose A, Drexl A. Facility location models for distribution system design. Euro J Oper Res. 2004 Apr;162(1): 4-29.

[15] Balinski ML. Integer programming: Methods, uses, computation. Manag Sci. 1965 Nov;12(3):253-313.

[16] Andreas K, Görtz S. A branch-and-price algorithm for the capacitated facility location problem. Euro J Oper Res. 2007 June;179(3):1109-1125.

[17] Wu L, Zhang X, Zhang J. Capacitated facility location problem with general setup cost. Comp \& Oper Res. 2006 May;33(5):1226-1241.

[18] Melkote S, Daskin MS. Capacitated facility location-network design problems. Euro J Oper Res. 2001 Mar;129(3):481-495.

[19] Kuehn AA, Hamburger MJ. A heuristic program for locating warehouses. Manag Sci. 1963 July;9(4): 643-666.

[20] Davis PS, Ray TL. A branch-bound algorithm for capacitated facilities location problem. Naval Res Log Quar. 1969 Oct;16(3):331-344.

[21] Akinc U, Khumawala BM. An efficient branch and bound algorithm for the capacitated warehouse location problem. Manag Sci. 1977 Feb; 23(6):585-594.

[22] Jacobsen SK. Heuristics for the capacitated plant location model. Euro J Oper Res. 1983 Mar;12(3): 253-261.

[23] Van Roy TJ. A cross decomposition algorithm for capacitated facility location. Oper Res. 1986 Feb;34(1): 145-163.

[24] Beasley JE. An algorithm for solving large capacitated warehouse location problems. Euro J Oper Res. 1988 Feb;33(3):314-325.

[25] Magnanti TL. Wong RT. Decomposition methods for facility location problems [Internet]. MIT: Operations Research Centre; 1986 [cited 2015 Oct 26]. Available from: http://dspace.mit.edu/bitstream/ 
handle/1721.1/5128/OR-153-86-24513129.pdf? sequence $=1$.

[26] Delmaire H, Diaz JA, Fernandez E, Ortega M. Reactive GRASP and Tabu search based heuristics for the single source capacitated plant location problem. Infor. 1999 Aug;37(3):194-225.

[27] Agar MC, Salhi S. Lagrangian heuristics applied to a variety of large capacitated plant location problems. J Oper Res Soc. 1998 Oct;49(10):1072-1084.

[28] Hindi KS, Pienkosz K. Efficient solution of large scale, single-source, capacitated plant location problems. J Oper Res Soc. 1999 Mar;50(3):268-274.

[29] Hinojosa Y, Puerto J, Fernandez F. A multi-period two-echelon multi-commodity capacitated plant location problem. Euro J Oper Res. 2000 June;123(2): 271-291.

[30] Alfieri A, Brandimarte P, D’Orazio S. LP-based heuristics for the capacitated lot-sizing problem: The interaction of model formulation and solution algorithm. Inter J Prod Res. 2002 Jan;40(2):441-458.

[31] Baldacci R, Hadjiconstantinou E, Maniezzo V, Mingozzi A. A new method for solving capacitated location problems based on a set partitioning approach. Comp \& Oper Res. 2002 Apr;29(4):365-386.

[32] Diaz JA, Fernandez E. A branch-and-price algorithm for the single source capacitated plant location problem. J Oper Res Soc. 2002 July;53(7):728-740.

[33] Ghiani G, Guerriero F, Musmanno R. The capacitated plant location problem with multiple facilities in the same site. Comp \& Oper Res. 2002 Nov;29(13): 1903-1912.

[34] Cortinhal MJ, Captivo ME. Upper and lower bounds for the single source capacitated location problem. Euro J Oper Res. 2003 Dec;151(2):333-351.

[35] Ahuja RK, Orlin JB, Pallottino S, Scaparra MP, Scutella MG. A multi-exchange heuristic for the single-source capacitated facility location problem. Manag Sci. 2004 Jun;50(6):749-760.

[36] Contreras, IA, Diaz JA. Scatter search for the single source capacitated facility location problem. Annals Oper Res. 2008 Jan;157(1):73-89.

[37] Chen $\mathrm{CH}$, Ting CJ. Combining Lagrange heuristic and ant colony system to solve the single source capacitated facility location problem. Trans Res Part E. 2008 Nov;44(6);1099-1122.

[38] Lai M, Sohn H, Tseng T, Chiang C. A hybrid algorithm for capacitated plant location problem. Exp Sys with App. 2010 Dec;37(12):8599-8605.

[39] Eiselt HA, Laporte G. Location of a new facility on a linear market in the presence of weights. Asia-Pacific J Oper Res. 1988 Jan;5:160-165.

[40] Guneri AF, Cengiz M, Seker S. A fuzzy ANP approach to shipyard location selection. Exp Sys with App. 2009 May;36(4):7992-7999.

[41] Peer SK. A multi-criteria procedure for the user interface components layout problem, Asia-Pacific J Oper Res. 2009 Apr;26(2):257-284.

[42] Li Y, Liu X, Chen Y. Selection of logistics centre location using axiomatic fuzzy set and TOPSIS methodology in logistics management. Exp Sys with App. 2011 Jun;38(6):7901-7908.

[43] Ozcan T, Celebi N, Esnaf S. Comparative analysis of multi-criteria decision making methodologies and im- plementation of a warehouse location selection problem. Exp Sys with App. 2011 Aug;38(8):9773-9779.

[44] ReVelle CS, Swain R. Central facilities location. Geog Analy. 1970 Jan;2(1):30-42.

[45] Erlenkotter D. A comparative study of approaches to dynamic location problems. Euro J Oper Res. 1981 Feb;6(2):133-143.

[46] Tervonen T, Figueira J. A survey on stochastic multi-criteria acceptability analysis methods. J Multi-Crit Dec Analy. 2008 Nov;15(1-2):1-14.

[47] ahdelma R, Hokkanen J, Salminen P. SMAA-stochastic multi-objective acceptability analysis. Euro J Oper Res. 1998 Apr;106(1):137-143.

[48] Hokkanen J, Lahdelma R, Miettinen K, Salminen P. Determining the implementation order of a general plan by using a multi-criteria method. J Multi-Crit Dec Analy. 1998 Sep; 7(5):273-284

[49] Lahdelma R, Salminen P. SMAA-2: stochastic multi-criteria acceptability analysis for group decision making. Oper Res. 2001 Jun;49(3):444-454.

[50] Lahdelma R, Miettinen K, Salminen P. Ordinal criteria in stochastic multi-criteria acceptability analysis (SMAA). Euro J Oper Res. 2003 May;147(1):117-127.

[51] Lahdelma R, Miettinen K, Salminen P. Reference point approach for multiple decision makers, Euro J Oper Res. 2005 Aug;164(3):785-791.

[52] Tervonen T, Lahdelma R, Dias JA, Figueira J, Salminen P. SMAA-TRI: A parameter stability analysis method for ELECTRE-TRI, In: Kiker GA, Linkov I, editors. Environmental Security in Harbors and Coastal Areas. Berlin: Springer, 2007; p. 217-231.

[53] Lahdelma R, Salminen P. Stochastic multi-criteria acceptability analysis using the data envelopment model. Euro J Oper Res. 2006 Apr;170(1):241-252.

[54] Hokkanen J, Lahdelma R, Salminen P. A multiple criteria decision model for analyzing and choosing among different development patterns for the Helsinki cargo harbor. Socio-Eco Plan Sci. 1999 Mar;33(1):1-23.

[55] Lahdelma R, Salminen P, Hokkanen J. Locating a waste treatment facility by using stochastic multi-criteria acceptability analysis with ordinal criteria. Euro J Oper Res. 2002 Oct;142(2):345-356.

[56] Menou A, Benallou A, Lahdelma R, Salminen P. Decision support for centralizing cargo at a Moroccan airport hub using stochastic multi-criteria acceptability analysis. Euro J Oper Res. 2010 Aug;204(3):624-629.

[57] Figueira J, Greco S, Ehrgott M, editors. Multiple criteria decision analysis: State of the art surveys. Springer: Science \& Business Media; 2005.

[58] [Tervonen T, Figueira JR, Lahdelma R, Dias JA, Salminen P. A stochastic method for robustness analysis in sorting problems. Euro J Oper Res. 2009 Jan;192(1):236-242.

[59] Tervonen T. SMAA: open source software for SMAA computations. Inter J Sys Sci. 2014 Jan;45(1):69-81.

[60] Ministry of Development [Internet] [cited 2015 Oct 26] Available from: http://www.kalkinma.gov.tr. 